日本原子力研究開発機構機関リポジトリ

Japan Atomic Energy Agency Institutional Repository

\begin{tabular}{|c|l|}
\hline Title & $\begin{array}{l}\text { Chemical reaction of lithium with room temperature atmosphere of } \\
\text { various humidities }\end{array}$ \\
\hline Author(s) & $\begin{array}{l}\text { Furukawa Tomohiro, Hirakawa Yasushi, Kondo Hiroo, Kanemura } \\
\text { Takuji, Wakai Eiichi }\end{array}$ \\
\hline Citation & Fusion Engineering and Design, 98-99, p.2138-2141 \\
\hline Text Version & Author's Post-print \\
\hline URL & $\underline{\text { https://jopss.jaea.go.jp/search/servlet/search?5046621 }}$ \\
\hline DOI & $\underline{\text { https://doi.org/10.1016/j.fusengdes.2014.11.019 }}$ \\
\hline Right & $\begin{array}{l}\text { C 2015. This manuscript version is made available under the } \\
\text { CC-BY-NC-ND 4.0 license } \\
\text { http://creativecommons.org/licenses/by-nc-nd/4.0/ }\end{array}$ \\
\hline
\end{tabular}




\title{
Chemical reaction of lithium with room temperature atmosphere of various humidities
}

\author{
Tomohiro Furukawa $^{\mathrm{a}}$, Yasushi Hirakawa ${ }^{\mathrm{a}}$, Hiroo Kondo ${ }^{\mathrm{a}}$, Takuji Kanemura ${ }^{\mathrm{a}}$, Eiichi Wakai ${ }^{\mathrm{a}}$ \\ ${ }^{a}$ Japan Atomic Energy Agency, 4002 Narita, O-arai, Ibaraki 311-1393, Japan
}

\begin{abstract}
When replacing lithium target components in the International Fusion Materials Irradiation Facility, the lithium adhering on the surface of components will chemically react with the surrounding atmosphere. In this study, we investigate the chemical reaction of pure lithium in room temperature air, oxygen, nitrogen, and argon of various humidities. In air, oxygen, and argon, the weight gain increases with time and humidity, and no significant difference is observed in these gases. In nitrogen, except for the test with $75 \%$ relative humidity (RH), the weight gain accelerates with time, and the weight gain rate decreases with increasing RH. We attribute the weight gain increase observed in low humidity to the acceleration due to lithium nitride formation. Upon increasing the moisture content of the gas, the main lithium reaction becomes lithium hydroxide formation.
\end{abstract}

Keywords: IFMIF, EVEDA, Lithium, Safety handling, Chemical reaction

\section{Introduction}

A key stepping stone for realizing fusion in the Demonstration Power Plant reactor [1] is developing structural materials that can withstand the $14 \mathrm{MeV}$ neutrons generated in the deuterium-tritium fusion reaction. Candidate materials have been tested within the framework of developing the International Fusion Materials Irradiation Facility (IFMIF), which is an accelerator-based neutron source based on the deuteronlithium stripping reaction. These studies cater to the objectives of the Engineering Validation and Engineering Design Activities (EVEDA) of the IFMIF and are performed under the Broader Approach activities [2].

As a major Japanese activity for the Lithium Target Facility of the IFMIF, we designed and constructed the EVEDA lithium test loop, which is the largest liquid lithium test loop in the world, and started validating it in 2012 [3, 4]. Along with the validation, we have been developing the technology for the safe handling of lithium since 2008. This technology development comprises three tasks: (a) extinguishing lithium fires, (b) chemical reactions of lithium on the event of a leak, and (c) removing lithium from the components. Tasks (a) and (b) are related to actions subsequent to lithium spills and involve selecting candidate materials for burning lithium [5-7] and evaluating the corrosion of materials potentially exposed to lithium spills at high temperatures [8]. Task (c) consists of experimental studies for replacing and/or decommissioning lithium components. In the IFMIF, for example, a back plate in the target assembly will be exchanged during the in-service period. In a previous study [9], we reported the experimental results for a lithium removal technique, which assumed that the lithium adhering to the exchanged components would be cleaned (i.e., we considered how pure lithium dissolves into candidate solvents such as ethanol or pure water). However, lithium adhering to the back plate will react chemically with the atmosphere during the back plate exchange.

Based on this scenario, we investigated the chemical reaction of pure lithium in room temperature air, oxygen, nitrogen, and argon of varying humidity to estimate the chemical reaction during back plate exchange.

\section{Experiments}

Two types of apparatus were used for these experiments. The apparatus shown in Fig. 1 was for the experiments involving varying humidity, and that shown in Fig. 2 was for pure gases.

In the experiments involving variable humidity, a cylindrical lithium sample $(13 \mathrm{~mm}$ diameter and $10 \mathrm{~mm}$ height) was placed in a test cell with inner dimensions of $47.5 \mathrm{~mm}$ (diameter) and $57.0 \mathrm{~mm}$ (height). In the test cell, the gas (i.e., air, oxygen, nitrogen, and argon) with various levels of humidity was supplied continually at $300 \mathrm{ml} / \mathrm{min}$. The test cell was installed in an argon glove box. The lithium sample was removed intermittently from the test cell to be weighed in the argon environment. The humidity was set at $25 \%, 50 \%$, and $75 \%$ relative humidity (RH), and the dew point was continually measured.

In the experiments involving pure gas, the test cell, whose dimensions were the same as for variable humidity experiments, was directly connected to the gas regulator of the appropriate gas cylinder. The gas pressure was set at $0.02 \mathrm{MPaG}$. To weigh the lithium sample, the test cell was intermittently removed from the gas regulator and transferred to the argon glove box. Once inside the glove box, the lithium sample was removed from the test cell and weighed. This procedure was repeated for each experiment: in air $\left(80 \% \mathrm{~N}_{2}\right.$ and $20 \% \mathrm{O}_{2}$ ), oxygen, and nitrogen. 
The conditions of each experiment are given in Table 1. The dew point given in this table is the average value obtained during the experiments, and the dew point for the pure gases (i.e., $-80^{\circ} \mathrm{C}$ ) is the published value for the given gas.

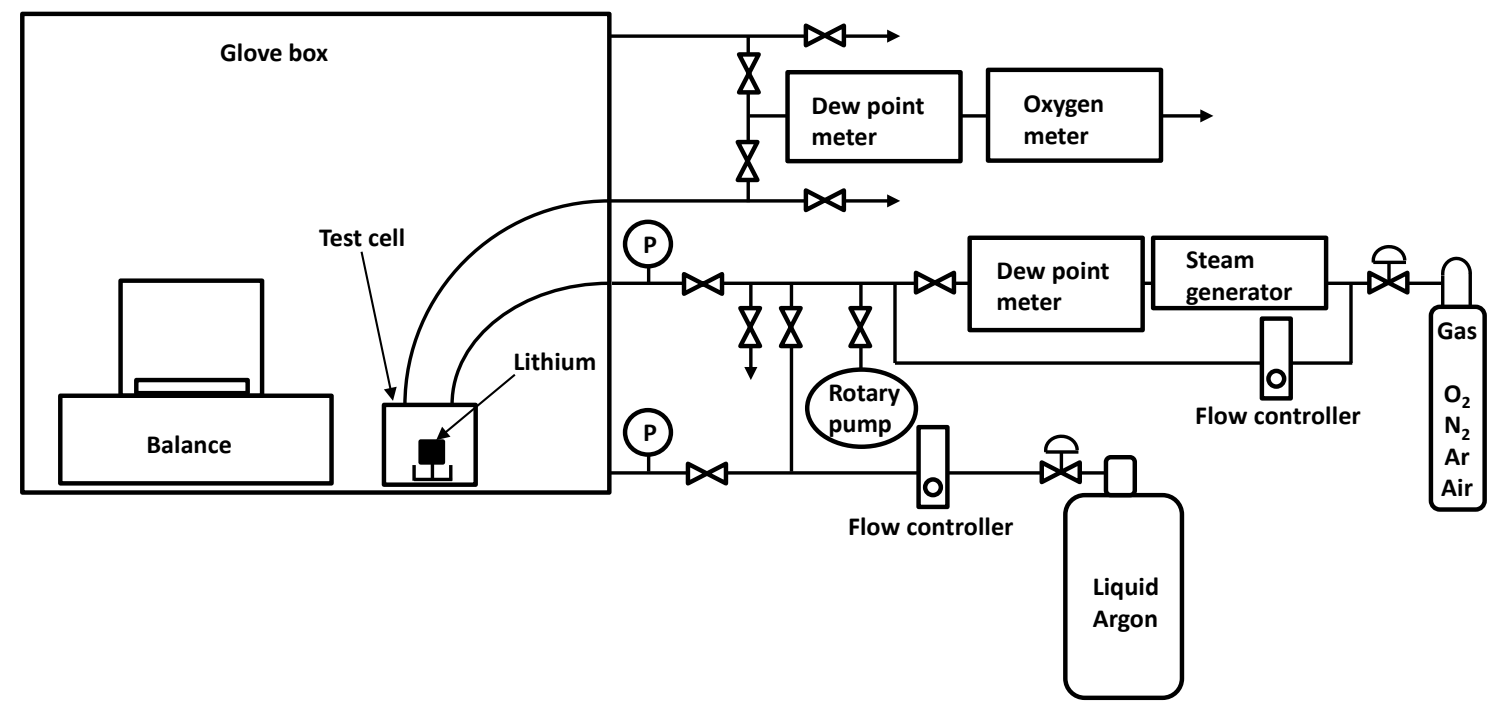

Fig. 1. Apparatus for the experiments containing variable humidity.

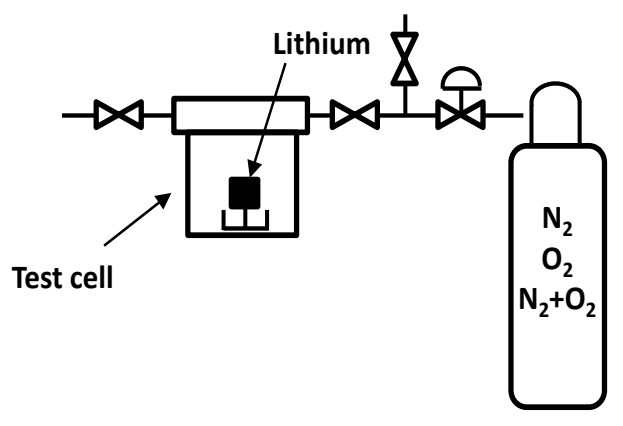

Fig. 2. Apparatus for the experiments in pure gas.

Table 1. Test condition

\begin{tabular}{|c|c|c|c|}
\hline Gas & Run No. & Target $\mathrm{RH}^{* 1} / \%$ & Dew point ${ }^{* 2} /{ }^{\circ} \mathrm{C}$ \\
\hline \multirow{4}{*}{ Oxygen } & $2-1$ & - & $(-80)$ \\
\hline & $1-1$ & 25 & 3.4 \\
\hline & $1-1$ & 50 & 13.8 \\
\hline & $1-3$ & 75 & 19.9 \\
\hline \multirow{5}{*}{ Nitrogen } & $2-2$ & 0 & $(-80)$ \\
\hline & $2-3$ & 0 & $(-80)$ \\
\hline & $1-4$ & 25 & 3.7 \\
\hline & $1-5$ & 50 & 13.8 \\
\hline & $1-6$ & 75 & 20.2 \\
\hline \multirow{5}{*}{ Air } & $2-4$ & - & $(-80)$ \\
\hline & $1-10^{* 3}$ & - & -15.4 \\
\hline & $1-7$ & 25 & 4.0 \\
\hline & $1-8$ & 50 & 13.4 \\
\hline & $1-9$ & 75 & 19.8 \\
\hline \multirow{3}{*}{ Argon } & 11 & 25 & 3.3 \\
\hline & 12 & 50 & 13.6 \\
\hline & $\begin{array}{r}13 \\
\end{array}$ & 75 & 19.8 \\
\hline \multirow[t]{2}{*}{ note } & ${ }^{* 1} \mathrm{RH}: \mathrm{rel}$ & e humidity & \\
\hline & ${ }^{* 2}$ Measu & emperature & e) during the test. \\
\hline
\end{tabular}

\section{Results and Discussion}

The weight gain during the chemical reaction of lithium in air is shown in Fig. 3. The weight gain increases linearly with time. During the same time, the weight gain increases with humidity. This behavior is also observed in oxygen and argon. Fig. 4 compares the weight gain slopes (hereinafter referred to as "weight gain rate"). As compared with the results for air, the data for oxygen and argon are mutually consistent within $\pm 25 \%$.

As stated above, the weight gain ratio in air (i.e., $80 \% \mathrm{~N}_{2}$ and $20 \% \mathrm{O}_{2}$ ) and oxygen is the same as that in an inert gas (e.g., Ar), which means that the major reaction was with $\mathrm{H}_{2} \mathrm{O}$, and oxygen and nitrogen had only a minor effect on the weight gain ratio. In these gaseous environments (i.e., in $\mathrm{Li}-\mathrm{O}-\mathrm{N}-\mathrm{H}$ systems), the following main thermochemical reactions occur:

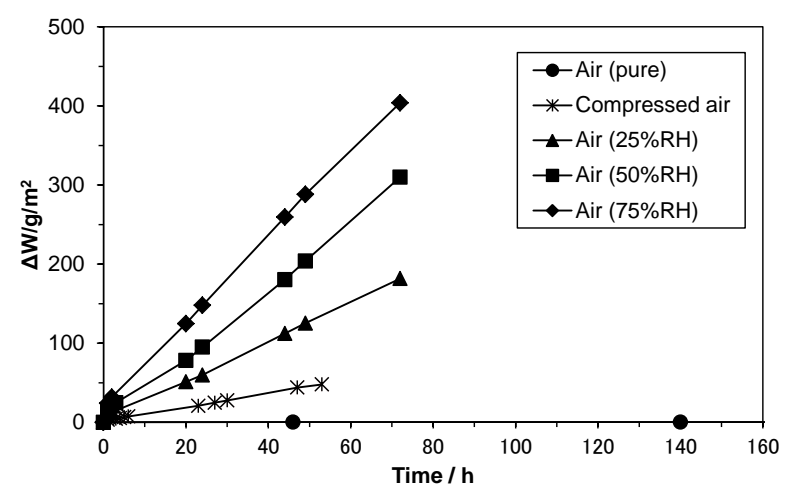

Fig. 3. Weight gain in air. 


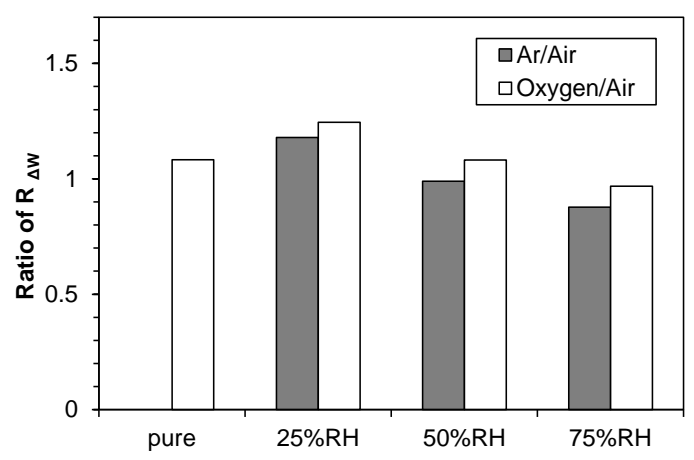

Fig. 4. Comparison of weight gain ratio.

$\mathrm{Li}[\mathrm{s}]+1 / 2 \mathrm{O}_{2}[\mathrm{~g}]=1 / 2 \mathrm{Li}_{2} \mathrm{O}[\mathrm{s}], \Delta \mathrm{rH}^{\circ}{ }_{298 \mathrm{~K}}=-299 \mathrm{~kJ} / \mathrm{mol}$

$\mathrm{Li}[\mathrm{s}]+1 / 6 \mathrm{~N}_{2}[\mathrm{~g}]=1 / 3 \mathrm{Li}_{3} \mathrm{~N}[\mathrm{~s}], \Delta \mathrm{rH}^{\circ}{ }_{298 \mathrm{~K}}=-55 \mathrm{~kJ} / \mathrm{mol}$

$\mathrm{Li}[\mathrm{s}]+\mathrm{H}_{2} \mathrm{O}[\mathrm{g}]=\mathrm{LiOH}[\mathrm{s}]+1 / 2 \mathrm{H}_{2}, \Delta \mathrm{rH}^{\circ}{ }_{298 \mathrm{~K}}=-243 \mathrm{~kJ} / \mathrm{mol}$

However, the results with nitrogen differed, as is evident from Fig. 5. Except at 75\% RH, the weight gain increased during the nitrogen experiments. In pure nitrogen, an increasing slope (hereinafter referred to as the second slope) occurs at 50-70 h, as shown in Fig. 5(a). At the onset of the second slope, the samples become black (Fig. 6). The different weight gains between Runs 2-2 and 2-3 correspond to the spread of the color change and are considered to fall within the limits of experimental error. The saturated weight gain of Run 2-2 is less than that of Run 2-3. Based on analyzing the cross-section of the sample, we find that a nonreacted region appears in Run 2-2 (Fig. 6). From the color change that occurs during the experiments and the weight gain in other environments, we consider that a chemical reaction with nitrogen-containing impurities, such as air, occurs during the first stage, whereas the real reaction with pure nitrogen occurs during the second stage because the sample surface reacts with impurity gases during the experimental setup.

The relationship between weight gain rate and gas humidity (dew point) is shown in Fig. 7. The plots for nitrogen were calculated from both the first and second slopes of the weight gain.

The weight gain rate for nitrogen with 25\% RH (dew point $3.7^{\circ} \mathrm{C}$ ) was the highest of all the nitrogen experiments, and it decreased with increasing humidity. In addition, the weight gain rate in pure nitrogen (dew point $-80^{\circ} \mathrm{C}$ ) is the lowest of the nitrogen experiments. These results are observed not only during the accelerated stage (i.e., second slope) but also during the first slope. Except for the $75 \% \mathrm{RH}$ experiment (dew point $20^{\circ} \mathrm{C}$ ), the weight gain ratio is much higher than that obtained in other gases at any dew point, and the weight gain ratio at $75 \% \mathrm{RH}$ in nitrogen is approximately equivalent to that obtained with oxygen, air, and argon.

As stated above, the increase in weight during the experiments in air and oxygen are equivalent to that obtained in argon and is attributed to lithium hydroxide ( $\mathrm{LiOH}$ ) formation. However, because air is $80 \%$ nitrogen, it is unclear why the weight gain rate in air is similar to that in oxygen and argon. The weight gain in pure nitrogen (Runs 2-2 and 2-3) is much greater than that in pure air (Run 2-4) or pure oxygen (Run 2-1). Indeed, as confirmed by the chemical equilibrium calculation shown in Fig. 8, and considering where the condensed phases form with lithium in one cubic meter of air at $25^{\circ} \mathrm{C}$, lithium oxide compounds are much more stable than lithium-nitrogen compounds (the algorithm for the calculation is described in Refs. [8, 10]). In any case, the lithium-oxygen reaction is also likely to be kinetically favored at the beginning, and this reaction immediately inhibits the lithium-nitrogen reaction. This reasoning leads to the conclusion that the condensed phase is not lithium nitride $\left(\mathrm{Li}_{3} \mathrm{~N}\right)$ but lithium oxide $\left(\mathrm{Li}_{2} \mathrm{O}\right)$. In fact, we considered that, with a large volume of air surrounding the lithium sample, the lithium reacts with oxygen in the air.

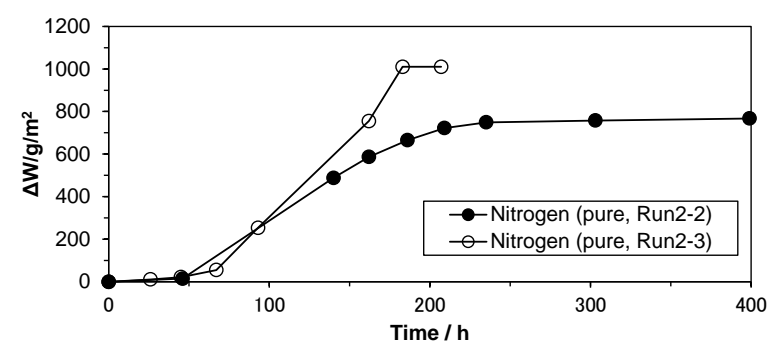

(a) in pure nitrogen

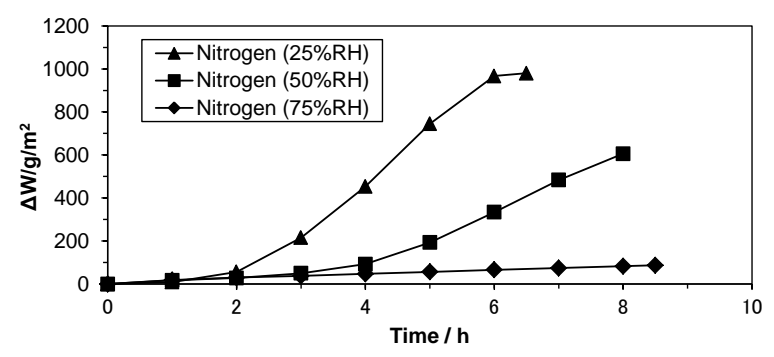

(b) in nitrogen containing $25 \%, 50 \%$ and $75 \%$ of $\mathrm{RH}$

Fig. 5. Weight gain in nitrogen.

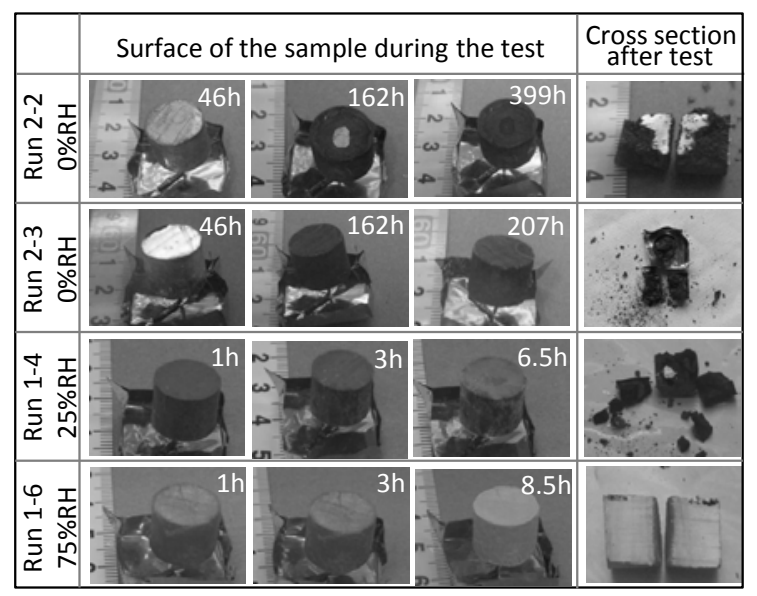

Fig. 6. Pictures of the samples in nitrogen. 
In nitrogen, although the weight gain rate increases because of the moisture in low humidity condition, it decreases when the moisture content is increased. The weight gain rate for $75 \% \mathrm{RH}$ is approximately the same as that obtained in oxygen, air, and argon at the same RH. The weight gain in low humidity nitrogen is accelerated by lithium nitride formation. Upon increasing the $\mathrm{RH}$, the main lithium reaction becomes lithium hydroxide formation. We consider that because the main chemical reaction in high humidity conditions is always lithium hydroxide formation, the weight gain rates for all gases are similar at $75 \% \mathrm{RH}$.

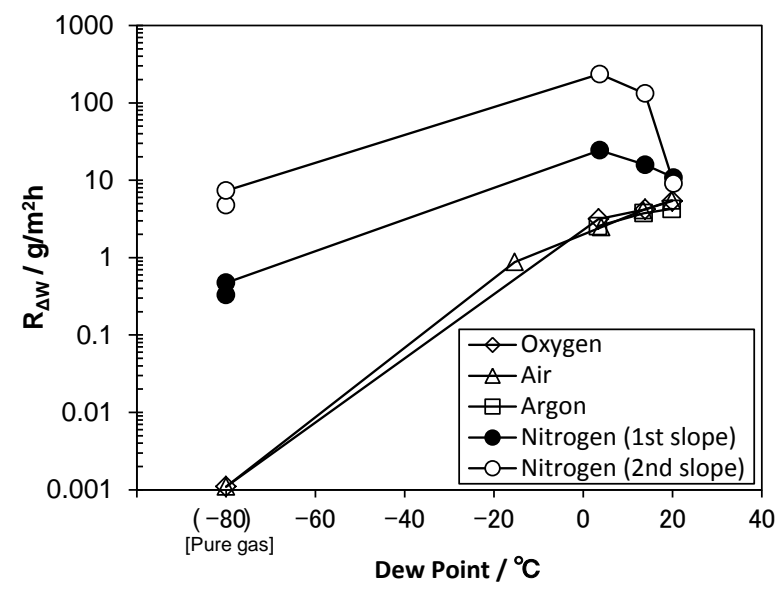

Fig. 7. Relationship between dew point in gas and weight gain rate.

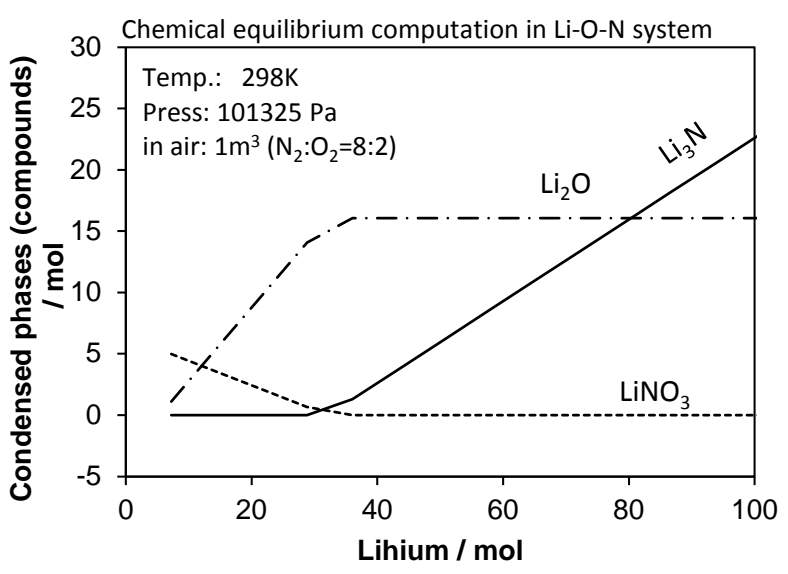

Fig. 8. Chemical equilibrium computation in Li-O-N system.

\section{Conclusion}

We investigated the chemical reaction of lithium in room temperature air, oxygen, nitrogen, and argon under various humidity levels.

In air, oxygen, and argon, the weight gain increases with time and humidity. No significant difference is observed for these gases.

In nitrogen, except for $75 \% \mathrm{RH}$, the weight gain accelerates over time, and the weight gain rate decreases with increasing $\mathrm{RH}$. The weight gain rate of nitrogen with $25 \% \mathrm{RH}$ is the highest of all nitrogen experiments.
In addition, the weight gain rate in pure nitrogen is less than that in nitrogen with nonzero humidity.

We consider that the increase weight gain observed in air, oxygen, and argon is due to lithium hydroxide formation. In nitrogen, although the weight gain rate increases due to moisture in low humidity conditions, it decreases upon increasing the humidity. We attribute the weight gain increase observed in low humidity to the acceleration due to lithium nitride formation. Upon increasing the humidity, the main reaction with lithium becomes lithium hydroxide formation.

Because the main chemical reaction under high humidity conditions is always lithium hydroxide formation, the weight gain rates in all four gases are similar for $75 \% \mathrm{RH}$.

\section{Acknowledgments}

The authors wish to thanks Mr. Shigeru Gunji and Mr. H. Tobita from Ascend Co. Ltd. for their assistance in the examination.

\section{References}

[1] A. Moeslang, U. Fischer, V. Heinzell, P. Vladimirov, R. Ferdinand, H. Klein, et al., Proceedings of the 19th Fusion Energy Conference, France, October, 2002, IAEACN94/FT1-2, 2002.

[2] J. Knaster, F. Arbeiter, P. Cara, P. Favuzza, T. Furukawa, F. Groeschel, et al., Nucl. Fusion 53 (2013) 116001 (18 pp.).

[3] H. Kondo, T. Furukawa, Y. Hirakawa, K. Nakamura, M. Ida, K. Watanabe, et al., Nucl. Fusion 51 (2011) 123008 (12 pp.).

[4] H. Kondo, T. Furukawa, Y. Hirakawa, H. Iuchi, T. Kanemura, M. Ida, et al., Fusion Eng. Des. 87 (2012) 418422.

[5] T. Furukawa, Y. Hirakawa, "Experimental Study on FireExtinguishing of lithium”, paper No. ICONE-18-29262, in: Proceedings of the 18th International Conference on Nuclear Engineering, May 17-21, Xi’an, China, 2010.

[6] T. Furukawa, H. Kondo, Y. Hirakawa, S. Kato, I. Matsushita, M. Ida, et al., Fusion Eng. Des. 86 (2011) 2433-2436.

[7] T. Furukawa, M. Ohtaka, Y. Hirakawa, "Experimental Study on Lithium Leakage Behavior”, paper No. ICONE22-30021, in: Proceedings of the 2014 22nd International Conference on Nuclear Engineering, July 711, Prague, Czech Republic

[8] T. Furukawa, Y. Hirakawa, S. Kato, Fusion Eng. Des. 88 (2013) 2502-2505.

[9] T. Furukawa, Y. Hirakawa, "Basic Experiment on Lithium Removal Technique”, paper No. ICONE-POWER201254209, in: Proceedings of the 2012 20th International Conference on Nuclear Engineering collocated with the ASME 2012 Power Conference, July 30-August 3, Anaheim, CA, USA, 2012.

[10] T. Matsumoto, H. Yokokawa, Netsu Sokutei 19 (4) (1992) 170-173 (in Japanese) 